\title{
\& Research Square

\section{Factors associated with patient satisfaction with perioperative anesthesia care at Hawassa university comprehensive specialized hospital, Ethiopia: Cross-sectional study design}

Amanu Gashaw Siraneh ( $\sim$ agashaw2020@gmail.com )

Hawassa University https://orcid.org/0000-0001-6988-4789

Getahun Dendir Welda

Wolaita Sodo University

Kebreab Paulos Chanko

Wolaita Sodo University

\section{Research}

Keywords: perioperative, Anesthesia, Satisfaction

Posted Date: May 1st, 2020

DOI: https://doi.org/10.21203/rs.3.rs-25754/v1

License: (c) (1) This work is licensed under a Creative Commons Attribution 4.0 International License.

Read Full License 


\section{Abstract \\ Background}

Patient satisfaction in relation to perioperative anesthesia care represents an essential aspect of quality health care management. The assessment of patient satisfaction is a reality of practice today for good patient satisfaction with health care provider interaction and health influencing factors.

\section{Objectives}

To assess the magnitude and associated factor of patient satisfaction towards anesthesia care at Hawassa University comprehensive specialized Hospital April 5, - May 5, 2019Gc.

\section{Method:}

A prospective cross-sectional study design was employed in an adult surgical patient scheduled for surgery under general anesthesia and the regional anesthesia level of satisfaction and factor associated with satisfaction was analyzed. Data was entered info version 7 and transfer to SPSS version 25.0 for analysis. Normality test checked by using Shapiro-Wilk and Kolmogorov-Smirnov the data was normally distributed. Then the frequency, percentage, and cross-tabulation with different variables were determined, lastly, the magnitude and associated factor analyzed by binary logistic regression a multivariate logistic regression. Variables P-value $<0.2$ binary logistic regression included in a multivariate logistic regression and p_value less than 0.05 was Taken as statistically significant.

\section{Result}

A Total of 200patient included in this study with a response rate of $100 \%$. The main finding of this study was predictors of perioperative patient dissatisfaction were general anesthesia, duration of surgery, nausea, and vomiting, and pain after surgery. The magnitude of patient satisfaction is $60 \%$. Odds of the patient who took general anesthesia were $2.31(1.096,4.142) p=0.026$ more dissatisfied than regional anesthesia. Odds of the patient duration of surgery $2-3 \mathrm{hr} 0.313(0.124,0.792)$ less likely dissatisfied than the duration of surgery $1 \mathrm{hr}$.The odds of patient nausea and vomiting AOR $=2.575(1.163,5.698) \mathrm{P}=002$ more likely dissatisfied than didn't have nausea and vomiting. The odds of patient pain after surgery AOR $=2.28(1.084,4.76)$ more likely dissatisfied than the patient didn't have pain after surgery.

\section{Conclusion}

patient satisfaction with perioperative anesthesia care Compared to another study magnitude of satisfaction very low, regular study and intervention should do every time /year in order to increase 


\section{Background}

Patient satisfaction is significant to measure quality care that can subsidize to balance the evaluation of the structure, process, and outcome of service. Several factors add to patient satisfaction, including availability and user-friendliness of service, the skill of health professionals, and clients own expectations $(1-4)$.

Patient satisfaction is a personal and complex thought involving physical, emotional, mental, social, cultural factors and predetermines consequences, such as nausea vomiting, pain complication and delivery of evidence before procedure affects the quality of health care $(2,5-7)$.

Sometimes postoperative complications such as residual sedation, pain, vomiting, and other complaints affect patient satisfaction. As a result, if appropriate management and preventive measure had not taken patient satisfaction and features of care may be hindered $(6,8)$.

Patient satisfaction is progressively more appreciated measure of quality for health care. Factors patients dissatisfied preoperatively were general anesthesia, intraoperative awareness, pain during the operation, and pain immediately after operation (9). High satisfaction with perioperative anesthesia care relations between patient and anaesthetists during care and, absence of shivering and adequate postoperative pain control in the ward are significant prognosticators of patient satisfaction (10).

Patient satisfaction after anesthesia care is an important outcome for health care personnel, mainly for anesthesia providers. The assessment of patient satisfaction and the patient familiarity are key performance measures that are increasingly being used in compensation for performance plans, Institutional policies, training for healthcare providers, monitoring of patient outcomes, and documentation of monitoring activities. So the main objectives of this study to assess the magnitude and associated factor of patient satisfaction with anesthesia care.

\section{Method}

\subsection{Study design and patients}

The prospective cross-sectional study was conducted at Hawass university comprehensive Specialized Hospital, which is located $273 \mathrm{~km}$ away from Addis Ababa in the southern part of Ethiopia. Ethical approval was obtained from the ethical committee Hawassa University College of health science. Informed consent was taken from the study participant. All adult elective patients who will undergo surgery under anesthesia in HUCSH excluding Patients with an emergency, Day-case surgery, Psychiatric patient, Admission to ICU study period from April 5, -May 5, 2019. Because we use convince type of sampling technique, so sample size determination is not used. 


\subsection{Data collection}

Data was collected by using a Structured Questionnaire and cheek list which contains, an independent variable that supposed to be associated with outcome and the level of satisfaction. 5-point Likert scale used, in order to measure satisfaction level: 1, strongly satisfied 2. satisfied 3 neither satisfied nor dissatisfied 4 dissatisfied 5 strongly dissatisfied. During analysis respondents strongly satisfied and satisfied grouped under satisfied: 3 neither satisfied nor dissatisfied 4 dissatisfied 5 strongly dissatisfied classified under dissatisfied. The data was collected by 5 trend anesthesia students Data collectors and supervisors were trained for a half-day on each item included in the study tools, objective, relevant of study, right of respondents, the confidentiality of information obtained. Regular supervision and follow up was made during data collection. Investigator was a check for completeness and consistency of data every day.

\subsection{Data analyzing}

Data were entered e-info version 7 and transfer to SPSS version 25.0 for analysis. Normality test checked by using Shapiro-Will and Kolmogorov-Smirnov the data was normally distributed. Then the frequency, percentage, and cross-tabulation with different variables were determined, lastly, the magnitude and associated factor analyzed by binary logistic regression a multivariate logistic regression. Variables $P$-value $<0.2$ binary logistic regression included in a multivariate logistic regression and p_value less than 0.05 was taken as statistically significant.

\subsection{Operational definitions}

- Satisfaction - meeting the apparent needs and the anticipations of the clients in relative to factors related to the health care worker and facilities

- Client - An individual who purchases or uses a good or service

- Quality - An essential or characteristics or nature as belonging to or distinguish a thing

- Service - Providing accommodation and activities required by the public or others.

- Very satisfied - Absolutely, awfully meet the expectations, needs or desires of someone,

- Neutral - Have not good or bad feelings at the same time.

- Dissatisfied - Who are unhappy or disappointed with a situation?

- 5-point Like-rt scale A type of psychometric response scale in which respondents specify their level of agreement to a statement typically in five points used, in order to measure satisfaction level .1, strongly satisfied 2.satisfied 3 neither satisfied nor dissatisfied 4 dissatisfied 5 strongly dissatisfied

\section{Results}




\subsection{Socio-demographic characteristics of study participants}

A Total of 200patient included in this study with a response rate of $100 \%$. The magnitude of patient satisfaction is $60 \%$ (120) (fig1). The study enrolled $128(64 \%)$ male and $72(36 \%)$ female.75 (58.6\%) male patients were more satisfied than females. Majority of patient age distribution under 19-27 54(27\%), 2836 47(23.5\%) and 37-45 42(21\%).Most of the participant's educational levels grade 7-12 54(27\%), illiterate $48(24 \%)$, and grade 1-6 41(20.5\%).majority of participant educational level above grade 12 more satisfied than other educational levels.(tabel1)

Table 1 Socio demographic characteristics patient who undergo elective surgery under anesthesia at HUCSH in2019 Gc.

\begin{tabular}{|c|c|c|c|c|c|}
\hline \multicolumn{2}{|l|}{ Variable } & \multirow[t]{2}{*}{ Frequency $n(\%)$} & \multicolumn{2}{|c|}{ Satisfaction n (\%) } & \multirow[t]{2}{*}{ p-value } \\
\hline & & & satisfied & dissatisfied & \\
\hline \multirow[t]{7}{*}{ Age group } & $19-27$ & $54(27)$ & $29(60.4)$ & $26(39.6)$ & \multirow[t]{7}{*}{0.897} \\
\hline & $28-36$ & $47(23.5)$ & $30(63.8)$ & $17(36.2)$ & \\
\hline & $37-45$ & $42(21)$ & $24(57.1)$ & 18 (42.9) & \\
\hline & $46-54$ & $21(10.5)$ & $15(71.4)$ & $6(28.6)$ & \\
\hline & $55-63$ & 13(6.5) & 10(76.9) & $3(23.1)$ & \\
\hline & $64-72$ & $16(8)$ & $12(75)$ & $4(25)$ & \\
\hline & $>72$ & $7(3.5)$ & $3(42.9)$ & $4(57.1)$ & \\
\hline \multirow[t]{2}{*}{ Sex } & M & $128(64)$ & 75(58.6) & $53(41.4)$ & \multirow[t]{2}{*}{0.849} \\
\hline & $\mathrm{F}$ & $72(36)$ & $45(62.5)$ & $27(37.5)$ & \\
\hline \multirow[t]{5}{*}{ Educational status } & Illiterate & $48(24)$ & $30(62.5)$ & $18(37.5)$ & \multirow[t]{5}{*}{0.446} \\
\hline & Read \&write & $23(11.5)$ & 14(60.9) & $9(39.1)$ & \\
\hline & $1-6$ & $41(20.5)$ & $22(53.7)$ & $19(46.3)$ & \\
\hline & $7-12$ & $54(27)$ & 29(53.7) & $25(46.3)$ & \\
\hline & $>12$ & $34(17)$ & $26(76.5)$ & $8(23.5)$ & \\
\hline \multirow[t]{2}{*}{ Residency } & Urban & $99(49.5)$ & $61(61.6)$ & $38(38.4)$ & \multirow[t]{2}{*}{0.644} \\
\hline & Rural & $101(50.5)$ & $59(58.4)$ & $42(41.6)$ & \\
\hline
\end{tabular}

${ }^{\mathrm{n}}$ Number, ${ }^{\%}$ per cent

\subsection{Anesthesia and surgery associated risk factor that affects the magnitude of patient satisfaction}


The commonest type of anesthesia performed for the participants was regional anesthesia $56 \%(112)$. 78 (68.4) participants performed with regional anesthesia were more satisfied than general anesthesia $48(42.8 \%)$. Type of surgery performed was orthopaedic surgery $80(40 \%)$, general surgery $57(28.5 \%)$, gynaecology surgery $33(16.5 \%)$ and the least type of surgery was urologic30 $(15 \%)$. the patient underwent surgery for the first time $129(64.5 \%), 2-3$ times 59(29.5), and patients have undergone surgery for $>3$ times $12(6 \%)$. The majority of participant Length of surgical time 2-3h $98(49 \%)$ followed one-hour a $60(30 \%)$ and the remaining producers took. Patients more than 3 times undergo surgery were dissatisfied $5(51.7 \%)$ followed by patients undergone surgery for the first time 53(41.1\%).duration of surgery greater than $3 \mathrm{hr} 24(57.1)$ more dissatisfied followed by the duration of surgery $2-3 \mathrm{hr} 36(36.7 \%)$. the patient performed with regional anesthesia and duration of surgery statistically significant binary logistic regression $(p<0.05)$. (Tabel2)

Table 2. Anesthesia and surgery associated risk factor that affects satisfaction. Undergone elective surgery at, HUCSH, 2019GC.

\begin{tabular}{|c|c|c|c|c|c|c|}
\hline \multirow[t]{2}{*}{ Variable } & \multirow[t]{2}{*}{ Category } & \multirow[t]{2}{*}{ Frequency } & \multicolumn{2}{|l|}{ satisfaction } & \multirow{2}{*}{$\begin{array}{l}\text { C095\% C.I.for } \\
\text { EXP(B) }\end{array}$} & \multirow{2}{*}{$\begin{array}{l}\mathrm{p}- \\
\text { value }\end{array}$} \\
\hline & & & satisfied & dissatisfied & & \\
\hline \multirow[t]{2}{*}{ Types of anesthesia } & RA & $112(56)$ & $78(68.4)$ & $36(31.6)$ & 1 & \multirow[t]{2}{*}{$0.005 *$} \\
\hline & GA & $85(42.5)$ & $42(48.8)$ & $44(51.2)$ & $2.27(1.73,4.40)$ & \\
\hline \multirow[t]{4}{*}{ Type of surgery } & Urologic & $30(15)$ & $17(56.7)$ & $13(43.3)$ & $1.143(0.404,3.23$ & 0.801 \\
\hline & $\begin{array}{l}\text { General } \\
\text { surgery }\end{array}$ & $57(28.5)$ & $35(61.4)$ & $22(28.6)$ & $0.66(0,273,1,594)$ & 0.355 \\
\hline & Gynecology & $33(16.5)$ & $21(63.6)$ & $12(36.4)$ & $0.857(0.71,1.983)$ & 0.719 \\
\hline & Orthopedics & $80(40)$ & $47(58.8)$ & $(41.2)$ & 1 & \\
\hline \multirow{3}{*}{$\begin{array}{l}\text { Pervious number of } \\
\text { surgery }\end{array}$} & 1 & $129(64.5)$ & $76(58.9)$ & $53(41.1)$ & $0.992(0.299,3.29)$ & 0.99 \\
\hline & $2-3$ & $59(29.5)$ & $37(62.7)$ & $2(37.3)$ & $1.293(0.365,4.58)$ & 0.691 \\
\hline & 3 & $12(6)$ & $7(58.3)$ & $5(51.7)$ & 1 & \\
\hline \multirow[t]{3}{*}{ Duration of surgery } & 1 hour & $60(30)$ & $40(66.7)$ & $20(33.3)$ & 1 & \\
\hline & 2-3 hour & $98(49)$ & $62(63.3)$ & $36(36.7)$ & $4.47(1.92,10.41)$ & $0.001^{*}$ \\
\hline & $>3$ hour & $42(21)$ & $18(42.9)$ & $24(57.1)$ & $2.57(1.22,5.340$ & $0.013^{*}$ \\
\hline
\end{tabular}

${ }^{\mathrm{n}}$ Number,${ }^{\%}$ per cent, ${ }^{*}$ statically significant, cOR=crude odd ratio

\subsection{Post-operative complaints related to anesthesia cares that affect levels of patient satisfaction}

The postoperative complication in this study was shivering 59(29.5\%), pain after surgery54 (27\%), nausea and vomiting $49(24.5 \%)$, and sore throat 39 (19.5\%). the patient developed nausea and vomiting 
32(69.4\%) were more dissatisfied than didn't have nausea and vomiting. A patient who developed pain after surgery33 (58.9\%), sore throat 23(59\%) and shivering24 (40.7\%) more dissatisfied than those didn't developed .nausea and vomiting, sore throat and pain after surgery statically significant in binary logistic regression $(P<0.005)$.

Table3. Post-operative compliant associated with levels of satisfaction patient undergone elective surgery at HUCSH in2019GC.

\begin{tabular}{|c|c|c|c|c|c|c|}
\hline \multicolumn{2}{|l|}{ Postop variables } & \multirow{3}{*}{$\begin{array}{l}\text { Frequency n (\%) } \\
39(19.5 \%)\end{array}$} & \multicolumn{2}{|c|}{ Patient satisfaction $\mathrm{n}(\%)$} & \multirow{3}{*}{$\begin{array}{l}\text { COR.95\% CI } \\
2.623(1.283,5.362)\end{array}$} & \multirow{3}{*}{$\begin{array}{c}\text { p-value } \\
0.008^{*}\end{array}$} \\
\hline & & & satisfied & dissatisfied & & \\
\hline \multirow[t]{2}{*}{ sore throat after surgery } & yes & & $16(41)$ & $23(59)$ & & \\
\hline & no & $161(80.5 \%)$ & $104(64.6)$ & $57(35.4)$ & 1 & \\
\hline \multirow[t]{2}{*}{ Vomiting after } & yes & $49(24.5 \%)$ & 15 (30.6) & $32(69.4)$ & $2.970(1.561,5.651)$ & \multirow[t]{2}{*}{$0.001^{*}$} \\
\hline & no & $151(75.5 \%)$ & 105(69.5) & $46(30.5)$ & 1 & \\
\hline \multirow{2}{*}{$\begin{array}{c}\text { shivering after } \\
\text { surgery }\end{array}$} & yes & $59(29.5 \%)$ & $35(59.3)$ & $24(40.7)$ & $1.041(.560,1.93$ & \multirow[t]{2}{*}{0.899} \\
\hline & no & $141(70.5 \%)$ & $85(60.3)$ & $56(39.7)$ & 1 & \\
\hline \multirow{2}{*}{$\begin{array}{l}\text { pain after } \\
\text { surgery }\end{array}$} & yes & $54(27 \%)$ & $23(41.1)$ & $33(58.9)$ & $2.961(1.567,5.595)$ & \multirow[t]{2}{*}{$0.001 *$} \\
\hline & no & $146(73 \%)$ & $97(67.4)$ & $47(32.6)$ & 1 & \\
\hline
\end{tabular}

${ }^{\mathrm{n}}$ Number, ${ }^{\%}$ per cent, ${ }^{*}$ statically significant, cOR=crude odd ratio

\subsection{Perioperative Associated factors that affect patient dissatisfaction}

During bivariate analysis factors with a p-value, less than 0.25 were entered into multivariate regression. Multiple regressions revealed that type of anesthesia, duration of surgery, nausea, and vomiting, and pain after surgery significantly associated with after perioperative anesthesia dissatisfaction. Odds of the patient who took general anesthesia were $2.31(1.096,4.142) p=0.026$ more dissatisfied than regional anesthesia. Odds of the patient duration of surgery $2-3 \mathrm{hr} 0.313(0.124,0.792)$ less likely dissatisfied than the duration of surgery $1 \mathrm{hr}$.The odds of patient nausea and vomiting AOR=2.575(1.163,5.698) P=002 more likely dissatisfied than didn't have nausea and vomiting. The odds of patient pain after surgery $\mathrm{AOR}=2.28(1.084,4.76)$ more likely dissatisfied than the patient didn't have pain after surgery. (Tabel4) 


\begin{tabular}{|c|c|c|c|c|c|c|c|}
\hline \multirow[t]{2}{*}{ 'e. } & \multirow[b]{2}{*}{ category } & \multirow[t]{2}{*}{ Frequency (\%) } & \multicolumn{2}{|c|}{ Satisfaction Number (\%) } & \multirow[t]{2}{*}{ C0R 95\% CI } & \multirow[t]{2}{*}{ AOR95\% CI } & \multirow[t]{2}{*}{ P-value } \\
\hline & & & Satisfied & dissatisfied & & & \\
\hline \multirow[t]{2}{*}{ esthesia } & RA & $112(56)$ & $78(68.4)$ & $36(31.6)$ & 1 & 1 & \multirow[b]{2}{*}{0.026} \\
\hline & GA & $85(42.5)$ & $42(48.8)$ & $44(51.2)$ & $2.27(1.73,4.40)$ & $2.31(1.096,4.142)$ & \\
\hline \multirow[t]{4}{*}{ surgery } & $1 \mathrm{hr}$ & $60(30)$ & $40(66.7)$ & $20(33.3)$ & 1 & 1 & \\
\hline & $2-3$ & $98(49)$ & $62(63.3)$ & $36(36.7)$ & $4.47(1.92,10.41)$ & $0.313(0.124,0.792)$ & 0.14 \\
\hline & $>3 \mathrm{hr}$ & $42(21)$ & $18(42.9)$ & $24(57.1)$ & $2.57(1.22,5.340)$ & $0.507(0,222,1.61)$ & 0.108 \\
\hline & Yes & $39(19.5 \%$ & $16(41)$ & $23(59)$ & $2.623(1.283,5.36)$ & $2.12(0.881,5.153)$ & \multirow[t]{2}{*}{0.99} \\
\hline ry & no & $161(80.5 \%)$ & $104(64.6)$ & $57(35.4)$ & 1 & 1 & \\
\hline \multirow[t]{2}{*}{ fter surgery } & Yes & $49(24.5 \%)$ & $15(30.6)$ & $32(69.4)$ & $2.970(1.561,5.65)$ & $2.575(1.163,5.698)$ & \multirow[t]{2}{*}{0.02} \\
\hline & no & $151(75.5 \%)$ & $105(69.5)$ & $46(30.5)$ & 1 & 1 & \\
\hline \multirow[t]{2}{*}{ urgery } & Yes & $54(27 \%)$ & $23(41.1)$ & $33(58.9)$ & $2.961(1.567,5.595)$ & $2.28(1.084,4.76)$ & \multirow[t]{2}{*}{0.029} \\
\hline & no & $146(73 \%)$ & $97 \quad(67.4)$ & $47(32.6)$ & 1 & 1 & \\
\hline
\end{tabular}

${ }^{\mathrm{n}} \mathrm{Number},{ }^{\%}$ per cent, ${ }^{*}$ statically significant, $\mathrm{COR}=$ crude odd ratio,AOR=adjusted odd ratio

\section{Discussion}

Patient satisfaction is individual and complex thought, involving physical, emotional, mental, social, and cultural factors. It is determined by the excellence of the delivered care and the patient's anticipations of that care. $(2,11)$.in our studies a total of 200 participants were included. The magnitude of patient satisfaction was $120(60 \%)$.

On the contrary, our study low satisfaction compared to Belihun's total 149(99.3\%), Endale etal269 (98.1\%), and fekadu A.etal and Bnewu et al 120 (88.3\%) (10,12-14). This difference may be a sociodemographic factor, hospital community awareness towards surgery, organizational and structural preoperative setup and preoperative anaesthesia assessment and standard perioperative management patients to decrease postoperative patient complaints and subjective and complex concept of patient satisfaction.

In this study, socio-demographic factors age, sex, education level, and residency no significantly associated with the level of patient satisfaction. But a study conducted Endale et al extreme age less than 24 and above 65 lees satisfied than middle age group, Bnewu et al female participant more satisfied than male participant and more educated people are high satisfaction level $(13,14)$. This variation may be the subjective and complex concept of patient satisfaction.

A study was done by Ryder hospital by Bnewu et al and Gonder hospital Endale et al patient who operated regional anesthesia were more satisfied than general anesthesia $(13,14)$.Similarity due to 
regional anesthesia decrease nausea and vomiting, sore throat, shivering postoperative pain.

According to study done by p.s.myles,et al Australia surgical factors strong relation with patient dissatisfaction were nausea and vomiting, postoperative pain AOR=95\%, Cl $4.09(3.18,5.25)=95 \%, \mathrm{Cl}$ $3.94(3.16,4.96)$ and other postoperative compliant AOR=95\%, $\mathrm{Cl} 2.04(1.61,2.56)$ were predictors of perioperative patient dissatisfaction(6) .According to Bnewu et al Nausea and vomiting, pain, shortness of breath, and cold.In line with this research, our study showed a chance of dissatisfaction patient nausea and vomiting $A O R=2.575(1.163,5.698) P=002$ more likely dissatisfied than didn't have nausea and vomiting. The odds of patient pain after surgery $A O R=2.28(1.084,4.76)$ more likely dissatisfied than the patient didn't have pain after surgery. The reason for the similarity is due to include the same variable for postoperative complaint and patient experience feeling compliant as natural phenomena

The main finding of this study was predictors of perioperative patient dissatisfaction were general anaesthesia, duration of surgery, nausea and vomiting and pain after surgery

\section{Limitation of study}

The study didn't include large sample size,

\section{Conclusion}

Compared to another study magnitude of satisfaction very low, regular study and intervention should be done every time /year in order to increase patient satisfaction

\section{Recommendation}

Patient education about the effect of surgery and anesthesia should emphasize. Practice standards guidelines in order to decrease postoperative complaints. More emphasize should take in order to increase regional block and pain management

\section{Abbreviation}

C/S - cesarean section; ENT - Ear-nose-throat; GA - General anesthesia; HU - Hawassa University; HUCSH Hawassa University Comprehensive Specialized Hospital; OPD - Outpatient department; PROP - preoperation; QA - Quality assurance; RA - Regional Anesthesia; SA - Spinal Anesthesia; WHO - World health organization

\section{Declarations}

\section{Ethics approval and consent to participant}


Ethical clearance obtained from Hawass University College of medicine and health science and Official letter was written from the department of anesthesia. Written and verbal consent was obtained from each participant after a thorough explanation of the purpose.

\section{Consent for publication}

Not applicable.

\section{Availability of data and materials}

The datasets used and analyzed during the current study are available from the corresponding author on reasonable request. The finding of this research will be freely available to any scientist wishing to use them for non-commercial purposes, without breaching participant confidentiality.

\section{Competing interests}

The authors declare didn't have competing interests

\section{Funding}

The research was not funded.

\section{Authors' contributions}

All authors equal contribution

\section{Acknowledgments}

We would like to express our deepest heartfelt thanks to Hawassa University College of medicine and health science and department of anesthesia positive responses to facilitate this study. Our special thanks also go to study participants, data collectors.

\section{References}

1.Barnett SF, Alagar RK, Grocott MP, Giannaris S, Dick JR, Moonesinghe SR. Patient-satisfaction measures in AnesthesiaQualitative systematic review. Anesthesiology: The Journal of the American Society of Anesthesiologists. 2013;119(2):452-78.

2.Larson E, Sharma J, Bohren MA, Tunçalp Ö. When the patient is the expert: measuring patient experience and satisfaction with care. Bulletin of the World Health Organization. 2019;97(8):563.

3.Singh H, Haqq E, Mustapha N. Patients' perception and satisfaction with health care professionals at primary care facilities in Trinidad and Tobago. Bulletin of the World Health Organization. 1999;77(4):356. 
4. Trinh LN, Fortier MA, Kain ZN. Primer on adult patient satisfaction in perioperative settings. Perioperative Medicine. 2019;8(1):11.

5.Jala HA, Caljouw MA, Bedford NM, Hardman JG. Patient satisfaction with perioperative care among patients having orthopedic surgery in a university hospital. Local and regional anesthesia. 2010;3:49.

6.Myles P, Williams D, Hendrata M, Anderson H, Weeks A. Patient satisfaction after anesthesia and surgery: Results of a prospective survey of 10,811 patients. British Journal of anesthesia. 2000;84(1):610.

7.Hill S. The knowledgeable patient: communication and participation in health: John Wiley \& Sons; 2011.

8.Tong D, Chung F, Wong D. Predictive factors in global and anesthesia satisfaction in ambulatory surgical patients. Anesthesiology: The Journal of the American Society of Anesthesiologists. 1997;87(4):856-64.

9.Gebremedhn EG, Lemma GF. Patient satisfaction with the perioperative surgical services and associated factors at a University Referral and Teaching Hospital, 2014: a cross-sectional study. Pan African Medical Journal. 2017;27(1).

10.Belihun A, Alemu M, Mengistu B. A prospective study on surgical inpatient satisfaction with perioperative anesthetic service in Jimma University Specialized Hospital, Jimma, South West Ethiopia. J Anesth Clin Res. 2015;6(3):1-9.

11.M. A. A. Caljouw* MvBaFB. Patient's satisfaction with perioperative care: development, validation, and application of a questionnaire. Br J Anaesth 2008; 100:637-44.

12.Assefa F, Mosse A. Assessment of clients' satisfaction with health service deliveries at Jimma University specialized hospital. Ethiopian Journal of health sciences. 2011;21(2):101-10.

13.Benwu KM, Gebremedhin HG. A prospective study on elective surgical inpatient satisfaction with perioperative anesthesia service at Ayder comprehensive specialized hospital, Mekelle, Ethiopia. BMC anesthesiology [Internet]. 2019 2019/04//; 19(1):[46 p.]..

14.Gebremedhn EG, Chekol WB, Amberbir WD, Flatie TD. Patient satisfaction with anesthesia services and associated factors at the University of Gondar Hospital, 2013: a cross-sectional study. BMC research notes. 2015;8(1):377.

\section{Figures}




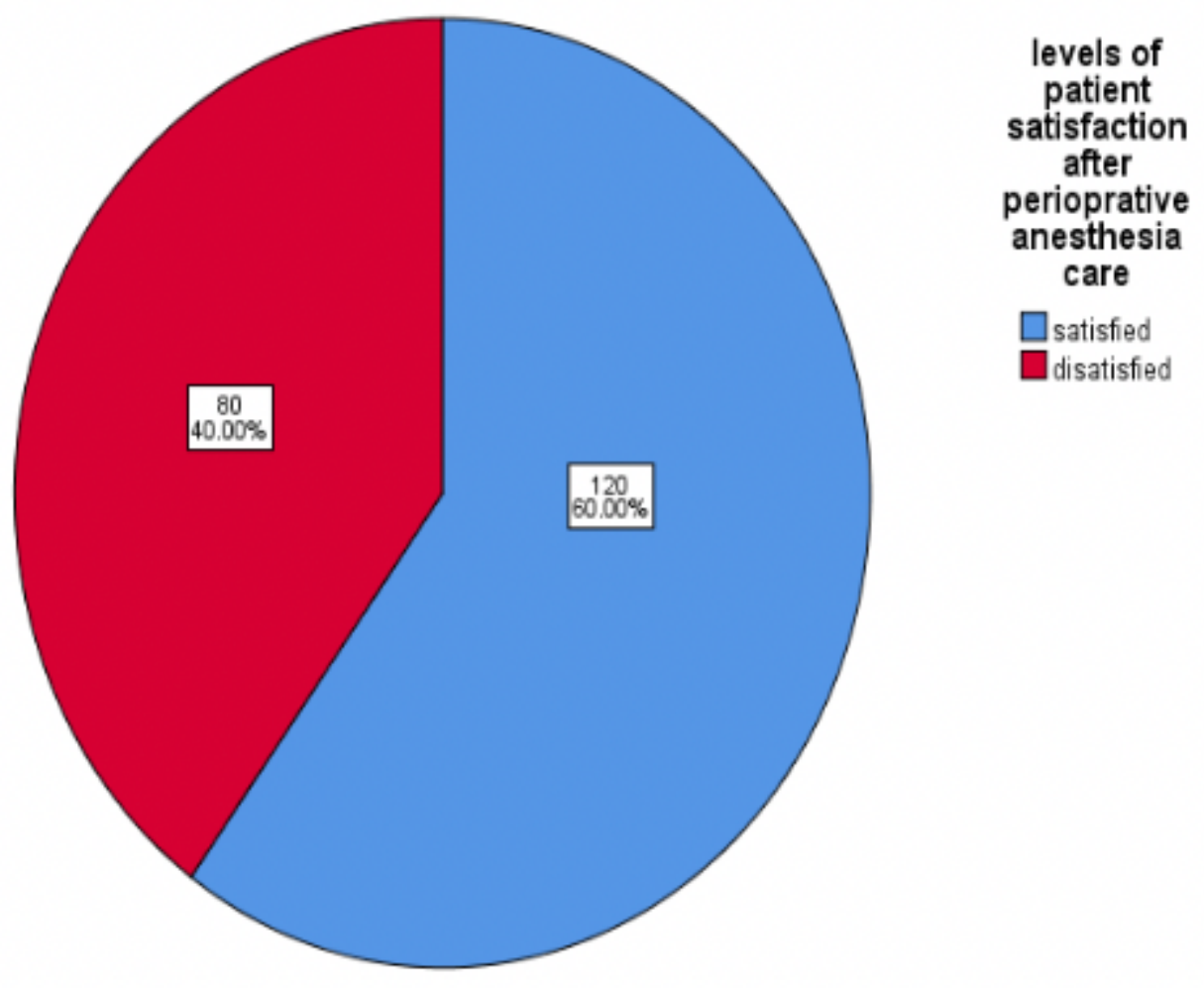

Figure 1

Magnitude of preoperative anesthesia care satisfaction patient under elective surgery from April 5 -may $52019 \mathrm{Gc}$

\section{Supplementary Files}

This is a list of supplementary files associated with this preprint. Click to download.

- STROBEsatisfaction1.docx

- STROBEsatisfaction1.docx 